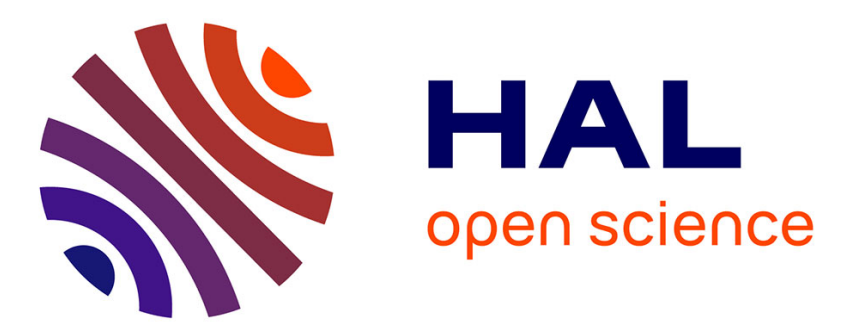

\title{
CFD-based evolutionary algorithm for the realization of target fluid flow distribution among parallel channels
}

\author{
Min Wei, Yilin Fan, Lingai Luo, Gilles Flamant
}

\section{To cite this version:}

Min Wei, Yilin Fan, Lingai Luo, Gilles Flamant. CFD-based evolutionary algorithm for the realization of target fluid flow distribution among parallel channels. Chemical Engineering Research and Design, 2015, 100, pp.341-352. 10.1016/j.cherd.2015.05.031 . hal-03155804

\section{HAL Id: hal-03155804 https://hal.science/hal-03155804}

Submitted on 2 Mar 2021

HAL is a multi-disciplinary open access archive for the deposit and dissemination of scientific research documents, whether they are published or not. The documents may come from teaching and research institutions in France or abroad, or from public or private research centers.
L'archive ouverte pluridisciplinaire HAL, est destinée au dépôt et à la diffusion de documents scientifiques de niveau recherche, publiés ou non, émanant des établissements d'enseignement et de recherche français ou étrangers, des laboratoires publics ou privés. 
Wei, M., Fan, Y., Luo, L., \& Flamant, G. (2015). CFD-based evolutionary algorithm for the realization of target fluid flow distribution among parallel channels. Chemical Engineering Research and Design, 100, 341-352. https://doi.org/10.1016/j.cherd.2015.05.031

(1)

\title{
CFD-based Evolutionary Algorithm for the Realization of Target Fluid Flow
}

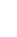

\author{
Min WEI ${ }^{\mathrm{a}}$, Yilin FAN ${ }^{\mathrm{a}}$, Lingai LUO ${ }^{\mathrm{a}}$, Gilles FLAMANT ${ }^{\mathrm{b}}$ \\ a Laboratoire de Thermocinétique de Nantes, UMR CNRS 6607, Polytech' Nantes - Université de Nantes, La \\ Chantrerie, Rue Christian Pauc, BP 50609, 44306 Nantes Cedex 03, France \\ ${ }^{b}$ Laboratoire Procédés, Matériaux et Energie Solaire (PROMES), UPR CNRS 8521, 7 rue du Four Solaire, \\ 66120 Font-Romeu Odeillo, France
}

\begin{abstract}
In energy and process systems, the bad fluid flow distribution (flow maldistribution) is one of the main causes of performance deterioration, equipment dysfunction, safety defaults, product quality degradation, reduced lifetime and over-cost. Flow equidistribution among numerous parallel channels is a classical goal, but is not always the optimal option according to a given objective and constraints. Target flow distribution (uniform or non-uniform) is far more difficult to achieve because it requires the precise control of flow-rate in given time for every channel. There is no such attempt in the existing literature.

In this study, a CFD-based evolutionary algorithm is developed to optimize the topology of an inserted perforated baffle, for the realization of target flow distribution among parallel channels. Several 2D numerical examples with different circuit geometries and different target curves are studied and compared. Results show that the optimized distribution curves obtained by performing the evolutionary algorithm are in good agreement with the target curves, with acceptable increase in pressure drop. This optimality algorithm may be easily applied to different working conditions. In this sense, the proposed algorithm is robust, effective, general and flexible, showing its promising application in various engineering fields dealing with fluid distribution problem.
\end{abstract}

\section{Keywords:}

Flow maldistribution; Evolutionary algorithm; Perforated baffle; Target curve; Parallel channels; CFD

\footnotetext{
* Corresponding author. Tel.: +33 240683167; Fax: +33 240683141. E-mail address: lingai.luo@univ-nantes.fr
} 


\section{Introduction}

The management of heat and mass transfer by fluid flow is a key issue for the design, the operation and the optimization of many industrial processes and energy conversion systems (Luo, 2013). Delivering precise and specified amounts of fluid in a given time and to the needed place in a fluid network is generally a desirable objective, but remains a crucial challenge. Flow maldistribution is one of the main causes of performance deterioration, equipment dysfunction, productivity reduction, product quality degradation, safety defaults, reduced lifetime and over cost of energy and process systems. Particularly for multi-tubular equipment in energy and process engineering, such as for heat exchangers (Fleming, 1967; Chiou, 1978; Lalot et al., 1999; Jiao et al., 2003; Wen and Li, 2004; Luo et al., 2007; Fan et al., 2008), fluidized beds (Maharaj et al., 2007; Ong et al., 2009), chemical reactors (Ponzi and Kaye, 1979; Heibel et al., 2001; Kobayashi et al., 2004; Wada et al., 2006; Inoue et al., 2007) or solar receivers (Chiou, 1982; Jones, 1987; Wang and $\mathrm{Wu}, 1990)$, flow distribution property of one or different fluids among a bundle of parallel channels usually plays an important role for the achievement of their expected efficiency. To realize the optimal flow distribution pattern of process equipment for a given application is an effective action of hydrodynamic control for process intensification.

Most of studies in the literature consider flow maldistribution as uneven flow distribution among parallel channels. Hence, flow equidistribution is a classical goal and many studies, either empirical or relevant to some kind of shape optimization, have been devoted to improve the flow distribution uniformity (e.g. Lalot et al., 1999; Commenge et al., 2002; Jiao et al., 2003; Luo et al., 2007; Rebrov et al., 2007; Fan et al., 2008; Saber et al., 2010; Yue et al., 2010; Tondeur et al., 2011; Kumaran et al., 2013; Guo et al., 2014; Al-Rawashdeh et al., 2014; etc.). Different types of flow equalization devices are proposed to create flow equidistribution, as summarized in Rebrov et al. (2011) and in Luo et al. (2015b).

However, the diversity of processes requires potentially many variations on the objective and under certain circumstances flow equidistribution is not necessarily the optimal distribution option. Researches on non-uniform but target flow distribution are relatively fewer and less recognized. Boerema et al. (2013) studied a multi-tubular solar receiver used in the concentrated solar power (CSP) plant, which absorbs concentrated solar radiation and transfers solar heat to a heat transfer fluid that circulates inside the tubes. They observed that the heat transfer fluid is preferably to be distributed unequally than uniformly among the parallel tubes due to the highly non-uniform distribution of solar irradiation on the receiver, so as to reduce the surface peak temperature and to extend the lifetime. Four kinds of tubular billboard design were investigated, including multi-diameter or multi-pass configurations, but a general method to realize the desired flow distribution subject to certain non-uniform heat flux radiation is still lacking. Milman et al. (2012) studied a tubular crossflow steam condenser which converts steam in the tube side from its gaseous to the liquid state by exchanging heat with the cooling fluid surrounding the tubes. They noticed that if steam is uniformly distributed among parallel tubes, the unequal heat removal due to the crossflow of cooling fluid will cause already sub-cooled condensate in some columns on the side of cooling fluid entrance whereas uncondensed steam existing in some columns on the other side. The optimal steam distribution in this case should guarantee that the condensation ends synchronously at the outlet of tubes, which implies certain degree of non-uniformity. The design of tubular condenser with variable channel lengths is usually proposed in industry. However, costly trial-and-error tests are requested and a simple and practical method for the realization of target non-uniform flow distribution is needed.

The above examples reveal the necessity of non-uniform but target fluid flow distribution in heat reactors, catalytic monoliths or micro heat sinks for cooling of electronic devices. The problem may be 
generalized as follows: for multi-tubular process equipment comprising of a number of parallel channels (or tubes) with identical geometry and dimension, there exists an optimal flow distribution among these channels so that best efficiency could be achieved subject to corresponding operating conditions. Flow equidistribution is optimal for some ideal conditions (uniform heat flux for solar receiver; countercurrent flow for steam condenser). But in most cases when actual operating condition deviates from the ideal one, the optimal flow distribution is non-uniform and may be described as a target curve. Once the optimal flow distribution curve is determined, the question behind is how to realize this target curve by a simple but practical method?

The existing literature survey indicates that flow equidistribution may be achieved through many approaches, either cost-effective or expansive. However, it is far more difficult to achieve the target flow distribution because it requires not simply the homogenization of fluid flow but the precise control of flow-rate for every channel to meet its target value. In fact, the flow equidistribution is just a special, and perhaps the simplest case of target flow distribution with flat (straight) target curve. To the best of our knowledge, rare investigations were reported in the open literature to propose practical methods for non-uniform but target fluid flow distribution.

As a generalization and extension of our earlier work on flow equidistribution (Luo et al., 2015a, b), this paper presents the development of a Computational Fluid Dynamics (CFD)-base evolutionary algorithm to realize the target flow distribution among parallel channels. The basic idea is to install a thin perforated baffle at the distributing manifold and to optimize the size and distribution of orifices, in order to reach the target flow-rate in every downstream channel. With respect to our earlier work (Luo et al. 2015b), the present work also concerns the geometry optimization of perforated baffle, but brings the following major advances:

- A general solution is provided for the realization of non-uniform target flow distribution which includes theoretically all kinds of possible forms, but not limited to flow equidistribution.

- The investigation takes the integral flow network into account, including the distributor, parallel channels and the collector, but is not limited to an individual fluid flow distributor.

- The optimization criterion is directly linked to the flow-rate passing through each channel instead of that in orifices, to meet the higher requirement raised by the non-uniform feature of target curve. This improvement may bring more effective adjustment of flow-rate in each channel, leading to more satisfying optimized results.

In the rest of this paper, we shall firstly introduce in the principle of the proposed evolutionary algorithm and the optimization procedure. Then several numerical cases on different geometries of equipment and different target distribution curves will be presented and discussed. Finally, main conclusions and perspectives will be summarized.

\section{CFD-based evolutionary algorithm}

We will describe in detail in this section the basic principles and steps of the CFD-based evolutionary algorithm with 2D examples. To simplify the numerical algorithm, we assume steady Newtonian fluid flow in this study.

\subsection{Parameter definition}


Figure 1 shows a representative schematic view of a multi-tubular equipment to tackle the problem of target flow distribution among parallel channels. The 2D fluid domain consists of 3 sections: inlet distributor, parallel channel array, and outlet collector. The inlet distributor has a single inlet tube of width $w_{i n}$, and a distributing manifold of $L_{\text {in }}$ in length and $H_{\text {in }}$ in height. Connected to the distributing manifold are $M$ parallel straight channels of identical width $d_{c h}$ and length $L_{c h}$, evenly spaced between the axis of one channel and another. For convenience of description, they are indexed by $k$ from 1 to $M$ from left to right. The endpoints of parallel channels are connected to the collector, which comprises of a collecting manifold of $L_{\text {out }}$ in length and $H_{\text {out }}$ in height, and a single outlet tube of width $w_{\text {out }}$. Note that the location of the inlet tube (or outlet tube) with respect to the distributing (or collecting) manifold can be on the edge (Fig. 4b), in the middle (Fig. 4a) or at any arbitrary position.

Fig. 1. Representative 2D schematic view of a multi-tubular equipment with insertion of a perforated baffle.

A perforated baffle with thickness $e$ is put forward to be installed inside the distributing manifold. The length of the baffle $(L)$ equals to the length of the distributing manifold $\left(L_{i n}\right)$, and the distance $S$ between the perforated baffle and the inlets of parallel channels is an adjustable parameter subject to optimization (Luo et al., 2015b). The baffle is divided into $M$ virtual control groups of identical length $\left(I_{C G}\right)$, also indexed by $k$ from 1 to $M$, each control group corresponding to a channel. As a result, the length of control group equals to the pitch between two channels.

$$
l_{C G}=\frac{L}{M}
$$

In $k$ th control group, there exists a number $(N)$ of virtual control areas of identical length $\left(I_{C A}\right)$. Each control area has one orifice of width $d_{k}$ arranged in the middle. Then following geometric relations can be easily obtained:

$$
\begin{gathered}
l_{C A}=\frac{l_{C G}}{N}=\frac{L}{N \times M} \\
\varepsilon_{k}=\frac{N d_{k}}{l_{C G}}=\frac{d_{k}}{l_{C A}} \\
\phi=\frac{N \sum_{k=1}^{M} d_{k}}{L}
\end{gathered}
$$

where $\varepsilon_{k}$ is defined as the local porosity in the $k$ th control group, which is equal to the local porosity in each control area of the kth control group, $\Phi$ the global porosity of the baffle.

When a certain fluid with constant mass flow-rate of $Q$ is supplied to the inlet tube, it will subsequently pass through the orifices of the baffle, the parallel channels and finally reach the outlet tube. We annotate the flow-rate passing through the $k$ th channel as $q_{k}$ and its target value as $q_{k}^{\prime}$. Based on mass conservation, we obtain: 


$$
Q=\sum_{k=1}^{M} q_{k}=\sum_{k=1}^{M} q_{k}^{\prime}
$$

$$
\bar{q}=\frac{Q}{M}
$$

where $\bar{q}$ is the mean mass flow-rate of all parallel channels.

Fig. 2. Basic principles of the evolutionary algorithm.

In this study, we follow the variation rule as presented in Eq. (7) from $t$ to $t+1$ iteration, which introduces a proportional relationship between the variation of $d_{k}$ and the departure of $q_{k}$ from its target $q_{k}^{\prime}$.

$$
\Delta d_{k, t}=d_{k, t+1}-d_{k, t}=\gamma\left(\frac{q_{k, t}^{\prime}-q_{k, t}}{\bar{q}}\right)
$$

$\gamma$ is a relaxation factor introduced to control the speed of variation. Following this variation rule, it can be observed that although the local porosity $\varepsilon_{k}$ changes from one iteration to the next, the global porosity of the baffle $\Phi$ is kept constant.

$$
N \sum_{k=1}^{M} \Delta d_{k, t}=\gamma N \sum_{k=1}^{M}\left(\frac{q_{k, t}^{\prime}-q_{k, t}}{\bar{q}}\right)=\gamma\left(\frac{N Q-N Q}{\bar{q}}\right)=0
$$

$$
\phi_{t+1}=\frac{N \sum_{k=1}^{M} d_{k, t+1}}{L}=\frac{N \sum_{k=1}^{M} d_{k, t}+N \sum_{k=1}^{M} \Delta d_{k, t}}{L}=\phi_{t}
$$

To avoid the potential possibility of overlap among the orifices, we assume that the boundary of control area and control group is fixed and the size of perforated orifices cannot overstep the boundary of control area during iterations. This implies:

$$
\varepsilon_{k}=\frac{d_{k}}{l_{C A}} \leq 1
$$




\subsection{Numerical implementation}

The evolutionary procedure is described in detail using the flow chart shown in Fig. 3.

(1) Input the initial data such as the size and initial geometry of multi-tubular equipment, the general operational conditions (the ambient temperature, operational pressure, with or without heat transfer, etc.), the physical characteristics of working fluid (fluid nature, total inlet flow-rate, density, viscosity, etc.) and the target flow distribution curve.

(2) Definition of the parameters relative to the perforated baffle, such as the location and thickness of baffle, the parameter $N$ and the global porosity of the baffle.

(3) Mesh generation of the whole simulation domain. Structured mesh is preferable for easy modification of simulation domain boundary.

(4) Calculation of the exact flow field at steady state, by solving the Navier-Stokes equations.

(5) Calculation of the mass flow-rate $q_{k}$ passing through each parallel channel; modification of the baffle configuration by comparing $q_{k}$ to $q_{k}^{\prime}$, according to the variation rule presented in Eq. (7).

(6) Regeneration of the mesh for updated simulation domain; recalculation of the exact flow field.

(7) Check the stable tolerance of the algorithm. If the tolerance is satisfied, then the evolutionary procedure is terminated. If not so, the procedure goes back to Step 3 for recurrence. The result is considered to be stable when the size variation at $t$ step $\Delta d_{k, t}$ is smaller than one cell size of the mesh. This also implies that the values of $q_{k}$ and $q_{k}^{\prime}$ are very close.

(8) Exportation of results, including the final configuration of perforated baffle, the values of mass flow-rate in every channel and the total pressure drop.

The degree of closeness between the target curve and the final flow distribution curve obtained by performing the evolutionary algorithm is quantified by the deviation factor (DF) defined as follow:

$$
\mathrm{DF}=\sqrt{\frac{1}{M-1} \sum_{k=1}^{M}\left(\frac{q_{k}-q_{k}^{\prime}}{q_{k}^{\prime}}\right)^{2}}
$$

The two curves $q_{k}$ and $q_{k}^{\prime}$ coincide completely when values of DF approach 0 . Note that Eq. (11) for flow deviation factor is a generalized form of flow maldistribution factor widely used to indicate the degree of non-uniformity in which $\bar{q}$ is replaced by $q_{k}^{\prime}$. Meanwhile, a dimensionless flow-rate ratio is also introduced for each channel:

$$
\mathrm{D} q_{k}=\frac{q_{k}-\bar{q}}{\bar{q}}
$$

\subsection{Calculation of flow field by CFD method}


An essential step of the evolutionary algorithm is the calculation of exact flow field. This generally involves solving Navier-Stokes equations by CFD methods. The equation for conservation of mass or continuity equation is:

$$
\frac{\partial \rho}{\partial t}+\nabla \cdot(\rho \vec{u})=0
$$

The momentum conservation equation is described by:

$$
\frac{\partial}{\partial t}(\rho \vec{u})+\nabla \cdot(\rho \vec{u} \vec{u})=-\nabla p+\nabla \cdot(\Pi)+\rho \vec{g}+\vec{F}
$$

Where $\vec{u}$ is the velocity, $p$ is the static pressure, $\rho \vec{g}$ and $\vec{F}$ are the gravitational body force and external body forces, $\Pi$ is the stress tensor which is given by:

$$
\Pi=\mu\left[\left(\nabla \vec{u}+\nabla \vec{u}^{\mathrm{T}}\right)-\frac{2}{3} \nabla \cdot \vec{u} I\right]
$$

where $\mu$ is the molecular viscosity, $l$ is the unit tensor.

The energy equation is:

$$
\frac{\partial}{\partial t}(\rho E)+\nabla \cdot(\vec{u}(\rho E+p))=\nabla \cdot(\lambda \nabla T)+\Pi: \nabla \vec{u}+\rho Q_{H}
$$

where $E$ is the internal energy, $\lambda$ is the thermal conductivity, and $Q_{H}$ includes the heat of chemical reaction, radiation and any other volumetric heat sources.

To predict turbulent flow pattern, additional turbulence models should be employed. It should be noted that the proposed evolutionary algorithm is somewhat independent of the CFD code used for the calculation of flow fields, regardless whether it is based on finite volume method, finite element method or more advanced techniques such as lattice Boltzmann method (Wang et al., 2010, 2014).

Having presented the basic principles and the procedure of the CFD-based evolutionary algorithm, its effectiveness on the realization of target flow distribution will be tested with different geometries of equipment and different target curves. It should be noted that numerical tests carried out in this study did not consider the thermal effect but concentrated on fluid flow. However, the algorithm developed is suitable for conditions with heat transfer, by taking into account the thermal effect in the CFD calculation.

\section{Simulation and results}

In this section, the simulation and results of several 2D cases are presented to show the feasibility of the proposed evolutionary algorithm. Two geometries of multi-tubular equipment are studied: one symmetric case with middle inlet and outlet (Fig. 4a); another asymmetric case with diagonal inlet and outlet (Fig. 4b). Various target curves are tested, including flat curve, ascending curve, descending curve and step-like curve.

Figure 4 shows the geometry and detail dimensions of studied multi-tubular equipment. The width of the inlet and outlet tube is $10 \mathrm{~mm}$. The length $\left(L_{\text {in }}\right)$ of the distributing manifold is $90 \mathrm{~mm}$ and the height $\left(H_{\text {in }}\right)$ is 


7

$15 \mathrm{~mm}$. Identical dimensions are used for the collecting manifold ( $L_{\text {out }}=90 \mathrm{~mm} ; H_{\text {out }}=15 \mathrm{~mm}$ ). There are fifteen parallel straight channels $(M=15)$ with identical width $\left(w_{c h}\right)$ of $2 \mathrm{~mm}$ and length $\left(I_{c h}\right)$ of $60 \mathrm{~mm}$. Note that the unique difference between two tested geometries is the position of inlet and outlet tubes, i.e. in the middle as axisymmetrical geometry (Fig. 4a) or in diagonal as nonaxisymmetrical geometry (Fig. 4b).

Fig. 4. Geometry and dimensions of studied multi-tubular equipment (unit: $\mathrm{mm}$ ). (a) middle inlet-outlet; (b) diagonal inlet-outlet.

The thickness (e) of the perforated baffle is $3 \mathrm{~mm}$ and the distance $(S)$ between the baffle and the inlet of parallel channels is $3.5 \mathrm{~mm}$. The baffle is divided into 30 control areas $(N=2)$, the length $\left(I_{C A}\right)$ of each control area thus being $3 \mathrm{~mm}$. The initial sizes of orifices are proposed as identical and equal to $1 \mathrm{~mm}$, the global porosity $(\Phi)$ being $33 \%$. Recall that according to Eq. (9), the global porosity $(\Phi)$ of the baffle is kept constant during iterations.

The working fluid used is water with density of $998.2 \mathrm{~kg} \cdot \mathrm{m}^{-3}$ and viscosity of $1.003 \times 10^{-3} \mathrm{~kg} \cdot \mathrm{m}^{-1} \cdot \mathrm{s}^{-1}$. The inlet velocity of fluid is set to be $0.1 \mathrm{~m} \cdot \mathrm{s}^{-1}$, the corresponding Re number being 1000 . The Re numbers in parallel straight channels range between 40 and 120 . The operational pressure is fixed at $101325 \mathrm{~Pa}$. In this study, simulations are performed under steady state, incompressible and isothermal condition without heat transfer. For simplification, gravity effect is neglected.

Fluid flow field in the fluid domain is calculated using a commercial code FLUENT (version 12.1.4). The fluid flow is calculated by the COUPLED method for pressure-velocity coupling, and second-order upwind differential scheme is applied for discretization of momentum and standard method for pressure. Constant velocity normal to the boundary of inlet surface is given and the boundary condition of outlet is set as pressure-outlet with zero static pressure. Adiabatic wall condition is applied and no slip occurs at the wall. The solution is considered to be converged when 1 ) sums of the normalized residuals for control equations are all less than $1 \times 10^{-6}$ and 2 ) the mass flow-rate at each channel is constant from one iteration to the next (less than $0.5 \%$ variation).

Structured mesh is generated using software ICEM (version 12.1) to build up the geometry model. Generally, one millimeter is divided into 20 segments to create square elemental cells. The influence of mesh density on the effectiveness of the evolutionary algorithm will be shown in later subsection with numerical example. At each optimization step, MATLAB is used to take the computed flow field results from FLUENT, perform calculations of the coordinates of simulation domain and pass the data required to ICEM to regenerate the mesh for the updated geometry.

\subsection{Middle inlet-outlet geometry}

Two target curves will be tested for the middle inlet-outlet geometry. The first is a flat curve implying uniform flow distribution while the second one is an ascending curve representing non-uniform flow distribution. These target curves can be described by the formulas below:

$$
q_{k}^{\prime}=\bar{q}=\frac{Q}{M} \quad(k=1,2, \ldots, 15)
$$

$$
q_{k}^{\prime}=\frac{(k-1)^{2}+196}{3955} Q \quad(k=1,2, \ldots, 15)
$$




\subsubsection{Flat target curve}

Figure 5 shows the flow-rate ratio of each channel under different conditions. When no baffle is stalled in the distributing manifold, the fluid tends to go preferentially into the channels facing the inlet tube. The flow distribution among parallel channels is obviously not uniform (maximum value of $D q_{k}$ is $58 \%$ ). The flow distribution is symmetrical about the central $8^{\text {th }}$ channel due to the axisymmetry of the geometry. The insertion of a uniformly perforated baffle (initial baffle) serves as an additional flow resistance to improve the uniformity to some extent, but still way off the target curve (maximum value of $D q_{k}$ is $23 \%$ ). By running the proposed evolutionary algorithm to adjust the sizes of orifices, uniform flow distribution among parallel channels can be achieved as shown by contour of velocity magnitude in Fig. 6 , indicated by the almost flat optimized distribution curve (maximum value of $\mathrm{D} q_{k}$ is $-1.4 \%$ ).

Figure 7 shows the evolution of DF values and the total pressure drop as a function of optimization steps. The step -1 represents the empty distributing manifold without baffle and the step 0 stands for the initial configuration of the baffle with identical size of orifices (same notations hereafter). It can be observed that the DF value reduces from 0.209 to 0.009 after 3 optimization steps, while the total pressure drop increases from 21.2 Pa to $24.0 \mathrm{~Pa}$. This case study implies that the proposed evolutionary algorithm is efficient for fluid flow homogenization. More details on the performance of evolutionary algorithm for uniform flow distribution, especially the effects of the baffle location, the initial size distribution of orifices and the global porosity can be found in our earlier work (Luo et al., 2015b).

Fig. 5. Flow distribution among parallel channels (middle inlet-outlet geometry; flat target curve).

Fig. 6. Contours of velocity magnitude (middle inlet-outlet geometry; flat target curve).

Fig. 7. Deviation factor (DF) and pressure drop $(\Delta p)$ as a function of optimization step (middle inlet-outlet geometry; flat target curve).

\subsubsection{Ascending target curve}

An ascending target curve is also introduced to test the objective of non-uniform flow distribution, and the optimization results are shown in Fig. 8. Unlike the flat target curve case, the flow flux in channels 1-9 should be reduced while those in channels 10-15 should be raised to approach the target values. This raises a higher requirement to the optimization algorithm because a simple action of homogenization is not sufficient. It can be observed from Fig. 8 that using the proposed evolutionary algorithm, the ascending target curve can be largely approached. The value of DF reduces from 0.322 to 0.028 after 6 optimization steps while the total pressure drop increases from 21.19 Pa to $28.27 \mathrm{~Pa}$, as shown in Fig. 9. Compared to the flat target curve case, the optimization procedure is a bit longer and higher pressure drop is generated. However, 33\% increase in pressure drop is generally acceptable compared to the $91.3 \%$ reduction in DF. This case study indicates that the proposed CFD-based evolutionary algorithm is capable of realizing target asymmetrical flow distribution for an axisymmetrical geometry. 
Fig. 9. Deviation factor (DF) and pressure drop ( $\Delta p$ ) as a function of optimization step (middle inlet-outlet geometry; ascending target curve).

\subsection{Diagonal inlet-outlet geometry}

6

Three patterns of target curve are tested for the diagonal inlet-outlet geometry, including a descending curve, an ascending curve and a step-like curve. These target curves can be described by the formulas below:

$$
\begin{gathered}
q_{k}^{\prime}=\frac{(k-15)^{2}+196}{3955} Q \quad(k=1,2, \ldots, 15) \\
q_{k}^{\prime}=\frac{(k-1)^{2}+196}{3955} Q \quad(k=1,2, \ldots, 15)
\end{gathered}
$$

$$
q_{k}^{\prime}=\left\{\begin{array}{lc}
\frac{2}{3} \bar{q} & (k=1,2, \ldots, 5) \\
\bar{q} & (k=6,7, \ldots, 10) \\
\frac{4}{3} \bar{q} & (k=11,12, \ldots, 15)
\end{array}\right.
$$

\subsubsection{Descending target curve}

Unlike the middle inlet-outlet case, the initial flow distribution curve of the diagonal inlet-outlet geometry (without baffle) is nonaxisymmetric and irregular, due to the inherent nonaxisymmetry of the geometry tested. As shown in Fig. 10, the flow-rate achieves the highest value in channel 2 and then decreases rapidly to the lowest in channel 5 . After that, a monotonous increase of flow-rate appears till the channel 15 which is the farthest channel from the inlet tube. The insertion of perforated baffle of uniform-sized orifices would improve the distribution uniformity, but does not much alter the global shape of the distribution curve. It seems that the uniform perforated baffle is not efficient to achieve non-uniform flow distribution in a nonaxisymmetrical structure. By performing the proposed evolutionary algorithm however, a good agreement can be reached between the optimized distribution curve and the target.

Fig. 10. Flow distribution among parallel channels (diagonal inlet-outlet geometry; descending target curve).

As shown in Fig. 11, the value of DF is reduced by $95.1 \%$ from 0.350 to 0.017 in 8 optimization steps, at the cost of $29.8 \%$ increase in pressure drop (from $25.58 \mathrm{~Pa}$ to $33.20 \mathrm{~Pa}$ ). In fact, higher pressure drop is generally inevitable to change the normal distribution to a target curve. The evolutionary algorithm may propose an optimal structure with balanced energy cost and the achievement of distribution target. 
Fig. 11. Deviation factor (DF) and pressure drop $(\Delta p)$ as a function of optimization step (diagonal inlet-outlet geometry; descending target curve).

\subsubsection{Ascending target curve}

Right now, an ascending curve is considered to be the target. The flow distribution curves for initial shape (without baffle) and for uniform perforated baffle are the same as described for the descending target curve case. By comparing the initial distribution curve and the target curve (Fig. 12), it can be observed that great reduction in flow-rate is required for channels 1-3 facing the inlet tube while the fluxes in other channels are relatively closer to their target values.

Fig. 12. Flow distribution among parallel channels (diagonal inlet-outlet geometry; ascending target curve).

It can also be observed from Fig. 12 that the optimized distribution curve and the target curve are largely matched while noticeable discrepancy may be found for channels 1-2. This is mainly due to the mesh density, i.e. the minimum amount of geometry change is one mesh cell. In this study, one millimeter is divided into 20 segments $(0.05 \mathrm{~mm}$ for a cell) for a compromise between accuracy and computational time. With this density, the value of DF decreases from 0.331 to about 0.028 in 7 steps but can not be reduced further, as shown in the left part of Fig. 13. Higher mesh density is favorable for a subtle modification of baffle geometry thus has positive effect on the realization of target flow distribution. As shown in the right part of Fig. 13, the value of DF could be further reduced from 0.028 to 0.018 in three steps when the size of single cell is decreased from $0.05 \mathrm{~mm}$ to $0.02 \mathrm{~mm}$. Nevertheless, higher mesh density augments the computational burden and raises higher requirement on the precision of fabrication method.

Fig. 13. Deviation factor (DF) and pressure drop $(\Delta p)$ as a function of optimization step, influence of mesh density (diagonal inlet-outlet geometry; descending target curve).

\subsubsection{Step-like target curve}

The two target curves studied above are both gradual, and this time a step-like target curve is introduced to test the effectiveness of the proposed algorithm. The step-like curve is mathematically described in Eq. (21). Graphically, 15 parallel channels are classified into low flow-rate group (channels 1-5), middle flow-rate group (channels 6-10) and high flow-rate group (channels 11-15). Uniform flow distribution is required among channels of the same group but the ratio of high and low flux is 2 .

Fig. 14. Flow distribution among parallel channels, effect of partition walls (diagonal inlet-outlet geometry; step-like target curve).

By examining the optimized curve (shown by marker $\Delta$ ) in Fig. 14, it can be observed that the step-like target curve (shown by marker *) can be satisfied only in tendency. The fluid fluxes in channels 6 and 11 can not rise to their target values while those in channels 1-5 are higher than the set value. This is because 
when a flow-rate jump is required from one channel to its neighbor, i.e. from channel $5(10)$ to channel 6 (11), high velocity gradient exists so that a transversal flow flux is inevitable at the remixing area between the perforated baffle and the channel inlets. As a result, the flow-rate in the first channel of step (channel 6 and channel 11) is difficult to reach its target value.

If a more satisfying optimized distribution curve is expected, a practical solution that can be easily employed is adding partition walls between the baffle and the channel inlets, to avoid the transitional flow flux. A comparative test is then carried out. As shown in Fig. 15b, two partition walls are installed in the middle of channels 5 and 6 , and of channels 10 and 11 , respectively. Other numerical parameters are kept unchanged. In this situation, the optimization objective is to realize uniform flow distribution in three separated groups isolated from each other. The optimized curve of the improved method (shown by marker $\nabla$ ) is also shown in Fig. 14. It can be observed that the optimized flow fluxes in channels 6 and 11 are closer to their target values, implying a good accordance between the optimized curve and the target curve.

Fig. 15. The effect of parathion walls on the flow field. (a) without partition walls; (b) with partition walls.

The effect of partition walls on the controlled flow distribution is shown in Fig. 16. It can be observed that the value DF can be further reduced from 0.052 to 0.019 by adding partition walls with a negligible increase in total pressure drop. This case study indicates that when target flow-rate gradient is important between two neighboring channels, adding partition walls to avoid the transitional flux is an effective solution, as shown in Fig. 15.

Fig. 16. Deviation factor (DF) and pressure drop $(\Delta p)$ as a function of optimization step, effect of partition walls (diagonal inlet-outlet geometry; step-like target curve).

\subsection{The configurations of the optimized perforated baffle}

Figure 17 shows the dimension distribution of orifices on the optimized perforated baffle subject to different target curves. A dimensionless diameter ratio $\left(D d_{k}\right)$ is introduced for each orifice for comparison:

$$
\mathrm{D} d_{k}=\frac{d_{k}-\bar{d}}{\bar{d}}
$$

where $\bar{d}$ is the average diameter of all orifices. 
Obviously, the optimal dimensions of orifices are very different from one case to another. For each case, it can be observed that the dimension distribution of orifices is roughly related to the difference between the initial distribution curve and the target distribution curve. This is logic since it is the basic principle of the evolutionary algorithm for optimization. However, quantitative relationships seem difficult to be obtained at this stage because of various interactions of fluid flows before and after they passing through the orifices, especially for cases of non-uniform target curves.

\section{Discussion and conclusions}

A CFD-based evolutionary algorithm is proposed for the realization of target flow distribution among parallel channels. The algorithm adjusts the size of orifices on the perforated baffle inserted in the distributing manifold so as to approach the target flow flux in every parallel channel. The effectiveness of the proposed evolutionary algorithm is tested by several 2D examples with different geometries (axisymmetric or nonaxisymmetric) and different target curves (uniform or non-uniform). Results show that for most of the cases, the optimized distribution curve rapidly reached by the algorithm is in good agreement with the target curve. The application of the algorithm is rather wide and promising. It can provide simple and practical solution for various engineering fields dealing with fluid distribution problem.

The influence of mesh density on the optimization results is analyzed through one special case. Generally, refined mesh (higher density) is favorable for more accurate calculation and more subtle modification of the baffle geometry. However, it raises higher requirements on computational facilities and the fabrication precision. Progressively refinement technique may be used to save the computation time. For practical applications of the algorithm in real engineering, the smallest cell size could be determined considering the fabrication precisions and tolerable deviation from the target curve.

The case study of "step-like" target curve shows that adding partition walls is effective to eliminate the transversal flux due to high flow-rate gradient between neighboring parallel channels. Hence this action can be considered as a useful complementary to the proposed algorithm. Under extreme operating conditions, partition walls may be installed for every "control group". The orifices in each control group functions as a "static valve" to adjust the desired flow-rate in the corresponding straight channel.

The perforated baffle may also be installed in the collecting manifold as additional resistance to adjust the fluid flow distribution. However, a preliminary test shows that the downstream control may not be as efficient as upstream control so it is not recommended. An alterative solution is to adjust the dimension of the inlet/outlet opening of every parallel channel as a supplemental hydraulic resistance. The optimized distribution of openings plays the role of integrated perforated baffle, leading to the target flow distribution among parallel channels. A systematic study on this method is one of the directions of our future work.

It should be noted that the efficiency of the proposed algorithm depends largely on simulated flow field while there is always a departure from the reality. Experimental validation of the proposed algorithm is also our ongoing work. This concerns the simulation and optimization of 3D objects, their fabrication and characterization. The extension of the heuristic algorithm for 3D applications is in principle straightforward and some guidelines can be found in Ref. (Luo et al., 2015b).

Finally, we shall return to the notion of "flow maldistribution". Flow maldistibution is usually considered as equivalent to non-uniform (uneven, inhomogeneous, etc.) flow distribution, meaning the common phenomenon of flow-rate difference among the different channels of multi-tubular equipment. The 
1 implication of this term is that any deviation from the uniform is considered as bad (mal)distribution. Under

2 real operating conditions however, the optimal flow distribution is usually not uniform but obeys certain

3 trend subject to a defined optimization objective and constraints. As a result, the notion of "flow

4 maldistribution" should be addressed in a broader context than uneven flow distribution: any flow

5 distribution that differs from the optimal distribution is referred as maldistribution. According to this new

6 definition, the parameter that indicates the departure between a certain distribution and its optimal shape,

7 i.e. the factor DF defined in Eq. (11), should be named as the general "maldistribution factor (MF)".

8 The proposed evolutionary algorithm for the realization of target distribution is just a small step to tackle 9 the flow maldistribution problem within its general framework. But behind all these, the deeper question is "what kind of flow distribution is the optimal"? This involves the determination of the "target curve" for a 11 process device or system, based on the defined objective function and constraints. This is also our on-going 12 work.

\section{Acknowledgement}

15 This work is partially financed by the French CNRS within the project AAP-Energie 2012 of INSIS. One of the 16 authors M. Min WEI would like to thank the "Région Pays de la Loire" for its partial financial support to his 17 PhD study. 


\section{Notations}

$\bar{d} \quad$ average diameter of all orifices $\quad \mathrm{m}$

$\begin{array}{lll}d_{c h} & \text { diameter of parallel channels } & \mathrm{m}\end{array}$

$\begin{array}{lll}d_{k} & \text { diameter of orifices } & \mathrm{m}\end{array}$

$\mathrm{D} d k \quad$ dimensionless diameter ratio

DF deviation factor

$\mathrm{D} q_{k} \quad$ dimensionless flow-rate ratio -

e thickness of the perforated baffle $\quad \mathrm{m}$

$E \quad$ internal energy per unit mass $\quad \mathrm{J} \mathrm{kg}^{-1}$

F external body force $\quad \mathrm{kg} \mathrm{m} \mathrm{s}^{-2}$

$g \quad$ gravitational acceleration $\mathrm{m} \mathrm{s}^{-2}$

$H_{\text {in }} \quad$ length of distributing manifold $\quad \mathrm{m}$

$H_{\text {out }} \quad$ length of collecting manifold $\quad \mathrm{m}$

I unit tensor

$l_{C A} \quad$ length of control area $\quad \mathrm{m}$

$l_{C G} \quad$ length of control group $\quad \mathrm{m}$

$L \quad$ length of baffle $\quad \mathrm{m}$

$L_{c h} \quad$ length of parallel channels $\quad \mathrm{m}$

$L_{\text {in }} \quad$ length of inlet tube $\quad \mathrm{m}$

$L_{\text {out }} \quad$ length of outlet tube $\mathrm{m}$

$M \quad$ number of parallel channels

$N \quad$ number of control areas in each control group -

$p \quad$ pressure $\quad \mathrm{Pa}$

$\bar{q} \quad$ mean mass flow-rate among parallel channels $\quad \mathrm{kg} \mathrm{s}^{-1}$

$q_{k} \quad$ mass flow-rate through channel $k \quad \mathrm{~kg} \mathrm{~s}^{-1}$

$q_{k}^{\prime} \quad$ objective mass flow-rate through channel $k \quad \mathrm{~kg} \mathrm{~s}^{-1}$

$Q \quad$ total inlet mass flow-rate $\mathrm{kg} \mathrm{s}^{-1}$

$Q_{H} \quad$ external heat transfer flux $\quad \mathrm{J} \mathrm{kg}^{-1} \mathrm{~s}^{-1}$

$\begin{array}{lll}S & \text { distance between baffle and parallel channels } & \mathrm{m}\end{array}$

$t \quad$ time step

T temperature $\quad \mathrm{K}$

$u$ velocity $\mathrm{m} \mathrm{s}^{-1}$

$w_{\text {in }} \quad$ width of inlet tube $\quad \mathrm{m}$

wout width of outlet tube $\quad \mathrm{m}$

2 Greek symbols

$\begin{array}{lll}\gamma & \text { relaxation factor } & - \\ \varepsilon & \text { local porosity } & - \\ \lambda & \text { thermal conductivity } & \mathrm{W} \mathrm{m}^{-1} \mathrm{~K}^{-1} \\ \mu & \text { viscosity } & \mathrm{kg} \mathrm{m}^{-1} \mathrm{~s}^{-1} \\ \Pi & \text { stress tensor } & - \\ \rho & \text { density } & \mathrm{kg} \mathrm{m}^{-3} \\ \Phi & \text { global porosity } & -\end{array}$

\section{Subscripts}

$k \quad$ channel and orifice index 
Al-Rawashdeh, M., Yu, F., Patil, N.G., Nijhuis, T.A., Hessel, V., Schouten, J.C., Rebrov, E.V., 2014. Designing flow and temperature uniformities in parallel microchannels reactor. AIChE Journal 60(5), 1941-1952.

Boerema, N., Morrison, G., Taylor, R., Rosengarten, G., 2013. High temperature solar thermal central-receiver billboard design. Solar Energy, 97, 356-368.

Chiou, J.P., 1978. Thermal performance deterioration in crossflow heat exchanger due to the flow nonuniformity. ASME Journal of Heat Transfer, 100, 580-587.

Chiou, J.P., 1982. The effect of nonuniform fluid flow distribution on the thermal performance of solar collector. Solar Energy, 29(6), 487-502.

Commenge, J., Falk, L., Corriou, J., Matlosz, M., 2002. Optimal design for flow uniformity in microchannel reactors. AIChE Journal, 48(2), 345-358.

Fan, Y., Boichot, R., Goldin, T., Luo, L., 2008. Flow distribution property of the constructal distributor and heat transfer intensification in a mini heat exchanger. AIChE Journal, 54(11), 2796-2808.

Fleming, R.B., 1967. The effect of flow distribution in parallel channels of counter-flow heat exchangers. Advances in Cryogenic Engineering, 12, 352-362.

Guo, X., Fan, Y., Luo, L., 2014. Multi-channel heat exchanger-reactor using arborescent distributors: A characterization study of fluid distribution, heat exchange performance and exothermic reaction. Energy, 69, 728-741.

Heibel, A.K., Scheenen, T.W.J., Heiszwolf, J.J., Van As, H., Kapteijn, F., Moulijn, J.A., 2001. Gas and liquid phase distribution and their effect on reactor performance in the monolith film flow reactor. Chemical Engineering Science, 56(21-22), 5935-5944.

Inoue, T., Schmidt, M.A., Jensen, K.F., 2007. Microfabricated Multiphase Reactors for the Direct Synthesis of Hydrogen Peroxide from Hydrogen and Oxygen. Industrial and Engineering Chemistry Research, 46(4), 1153-1160.

Jiao, A., Zhang, R., Jeong, S.K., 2003. Experimental investigation of header configuration on flow maldistribution in plate-fin heat exchanger. Applied thermal engineering, 23(10), 1235-1246.

Jones, G.F., 1987. Consideration of the heat-removal factor for liquid-cooled flat-plate solar collectors. Solar Energy, 38(6), 455-458. Microfluidic Device for Conducting Gas-Liquid-Solid Hydrogenation Reactions. Science, 304, 1305-1308. 
Kumaran, R.M., Kumaraguruparan, G., Sornakumar, T., 2013. Experimental and numerical studies of

2 header design and inlet/outlet configurations on flow mal-distribution in parallel micro-channels. Applied

3 Thermal Engineering, 58, 205-216.

4 Lalot, S., Florent, P., Lang, S., Bergles, A., 1999. Flow maldistribution in heat exchangers. Applied thermal 5 engineering, 19(8), 847-863.

6 Luo, L., 2013. Heat and Mass Transfer Intensification and Shape Optimization: A Multi-scale Approach. 7 Springer, London.

8 Luo, L., Fan, Y., Wei, M., Flamant, G., 2015a. Method for determing characteristics of holes to be provided 9 through a plate and corresponding programme. WO 2015/028758.

Luo, L., Fan, Y., Zhang, W., Yuan, X., Midoux, N., 2007. Integration of constructal distributors to a mini crossflow heat exchanger and their assembly configuration optimization. Chemical engineering science, 62(13), 3605-3619.

Luo, L., Wei, M., Fan, Y., Flamant, G., 2015b. Heuristic shape optimization of baffled fluid distributor for uniform flow distribution. Chemical Engineering Science, 123, 542-556.

Maharaj, L., Pocock, J., Loveday, B., 2007. The effect of distributor configuration on the hydrodynamics of the teetered bed separator. Minerals Engineering, 20(11), 1089-1098.

Milman, O.O., Spalding, D.B., Fedorov, V.A., 2012. Steam condensation in parallel channels with nonuniform heat removal in different zones of heat-exchange surface. International Journal of Heat and Mass Transfer, 55, 6054-6059.

Ong, B., Gupta, P., Youssef, A., Al-Dahhan, M., Dudukovic, M., 2009. Computed tomographic investigation of the influence of gas sparger design on gas holdup distribution in a bubble column. Industrial \& Engineering Chemistry Research, 48(1), 58-68.

Ponzi, P.R., Kaye, L.A., 1979. Effect of flow maldistribution on conversion and selectivity in radial flow fixed-bed reactors. AIChE Journal, 25(1), 100-108.

Rebrov, E.V., Ismagilov, I.Z., Ekatpure, R.P., de Croon, M.H.J.M., Schouten, J.C., 2007. Header design for flow equalization in microstructured reactors. AIChE Journal, 53(1), 28-38

Rebrov, E.V., Schouten, J.C., De Croon, M.H.J.M., 2011. Single-phase fluid flow distribution and heat transfer in microstructured reactors. Chemical Engineering Science, 66(7), 1374-1393.

Saber, M., Commenge, J.-M., Falk, L., 2010. Microreactor numbering-up in multi-scale networks for industrial-scale applications: Impact of flow maldistribution on the reactor performance. Chemical Engineering Science, 65(1), 372-379. 
1 Tondeur, D., Fan, Y., Commenge, J.-M., Luo, L., 2011. Uniform flows in rectangular lattice networks.

2 Chemical Engineering Science, 66(21), 5301-5312.

3 Wada, Y., Schmidt, M.A., Jensen, K.F., 2006. Flow distribution and ozonolysis in gas-liquid multichannel

4 microreactors. Industrial and Engineering Chemistry Research, 45(24), 8036-8042.

5 Wang, L., Fan, Y., Luo, L., 2010. Heuristic optimality criterion algorithm for shape design of fluid flow.

6 Journal of Computational Physics, 229(20), 8031-8044.

7 Wang, L., Fan, Y., Luo, L. 2014. Lattice Boltzmann method for shape optimization of fluid distributor.

8 Computers \& Fluids, 94(1), 49-57.

9 Wang, X., Wu, L., 1990. Analysis and performance of flat-plate solar collector arrays. Solar Energy, 45(2), $10 \quad 71-78$.

11 Wen, J., Li, Y., 2004. Study of flow distribution and its improvement on the header of plate-fin heat 12 exchanger. Cryogenics, 44(11), 823-831.

13 Yue, J., Boichot, R., Luo, L., Gonthier, Y., Chen, G., Yuan, Q., 2010. Flow distribution and mass transfer in 14 a parallel microchannel contactor integrated with constructal distributors. AIChE Journal, 56(2), 298-317. 


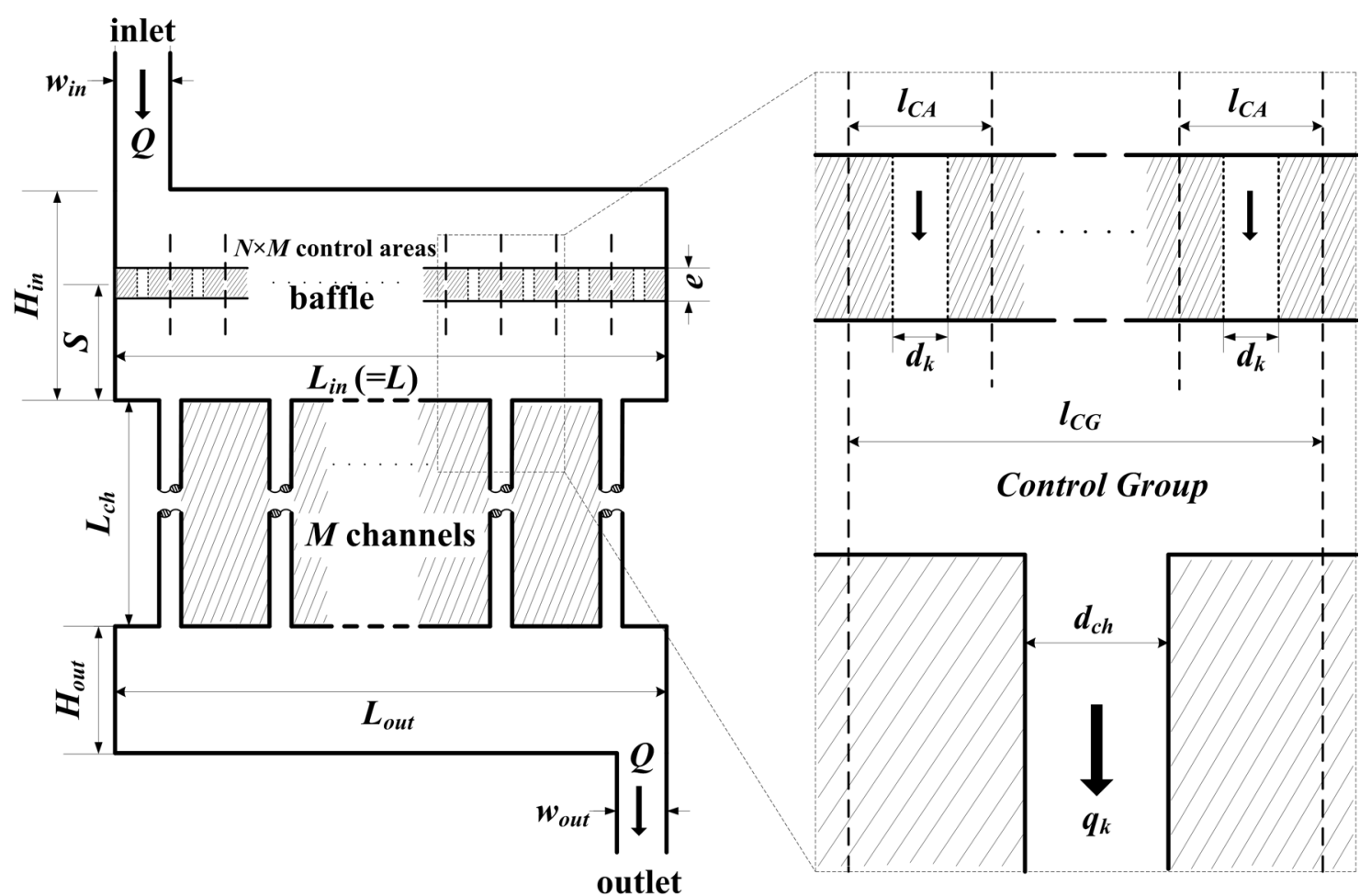

3 Figure 1. Representative 2D schematic view of a multi-tubular equipment with insertion of a perforated baffle.

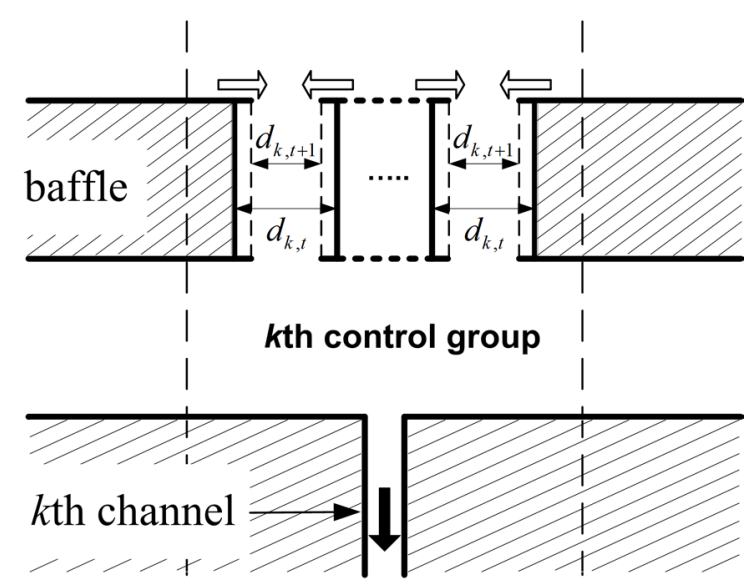

$$
q_{k, t}>q_{k, t}^{\prime}
$$




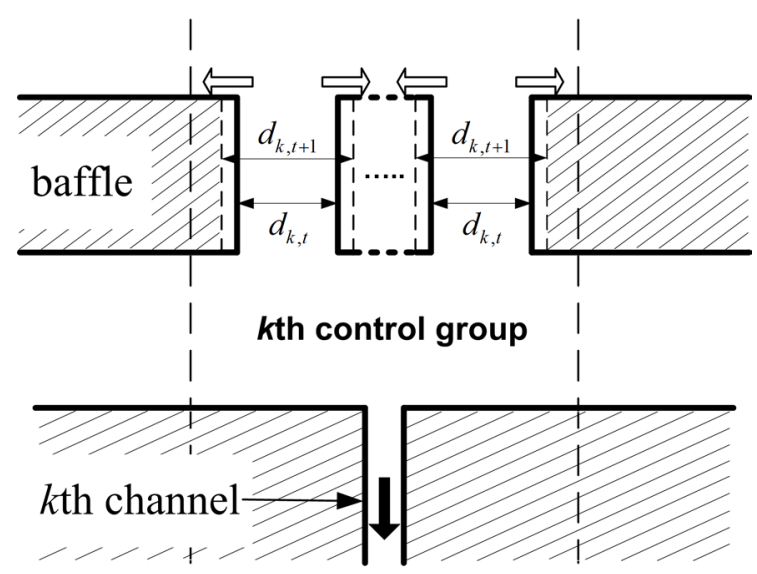

$$
q_{k, t}<q_{k, t}^{\prime}
$$

Figure 2. Basic principles of the algorithm.

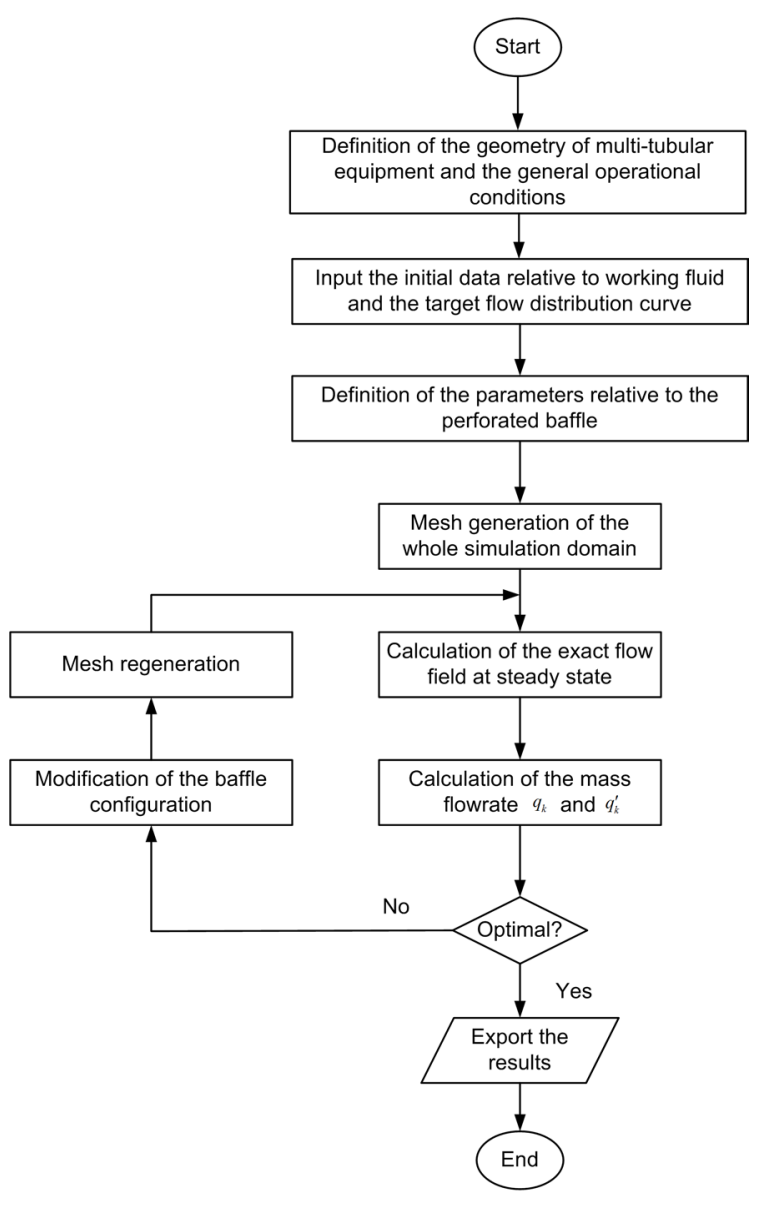

Figure 3. Flow chart of the algorithm. 


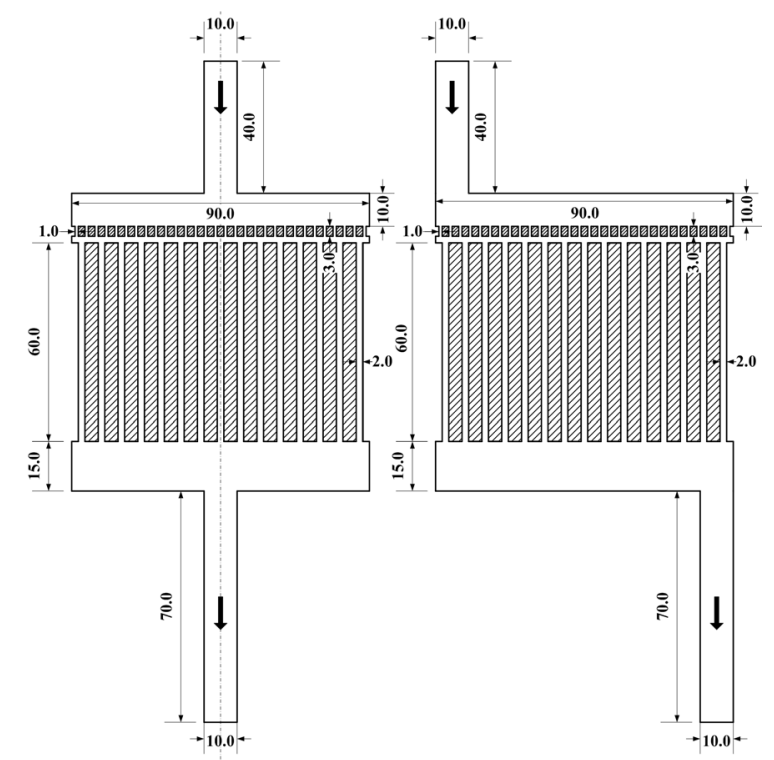

(b)

2 Figure 4. Geometry and dimensions of studied multi-tubular equipment (unit: $\mathrm{mm}$ ): (a) middle inlet-outlet; (b) diagonal inlet-outlet.

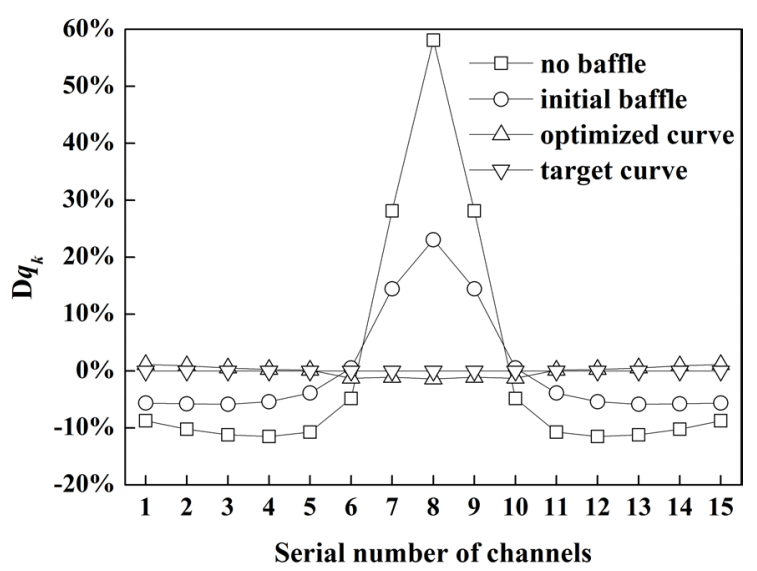

Figure 5. Flow distribution among parallel channels (middle inlet-outlet geometry; flat target curve). 


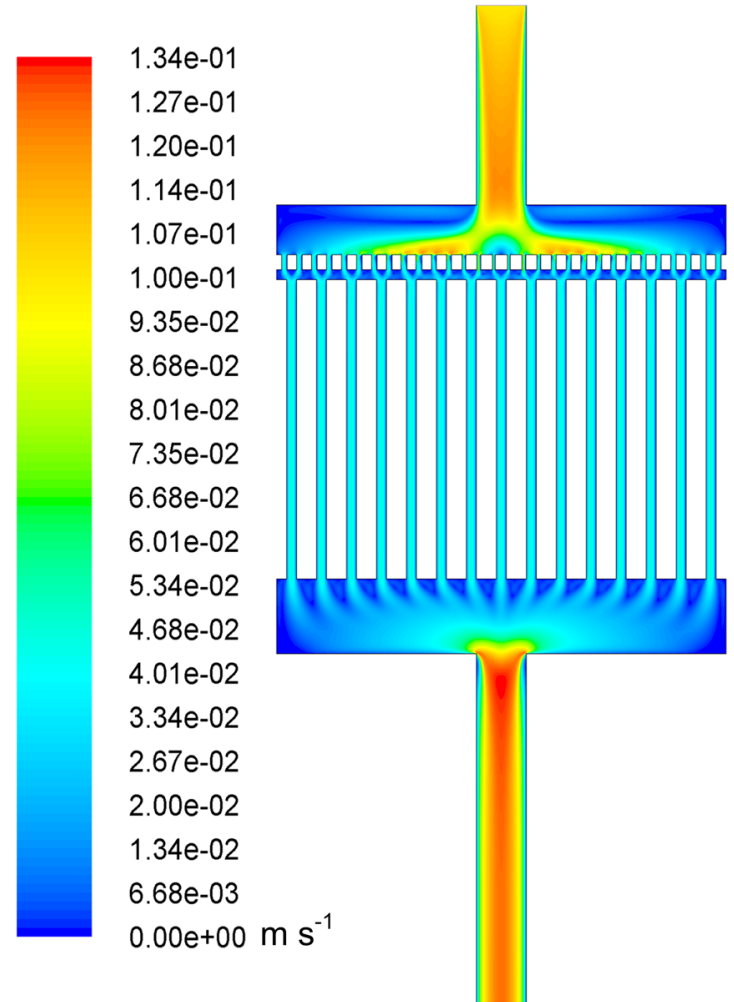

Figure 6. Contours of velocity magnitude (middle inlet-outlet geometry; flat target curve).

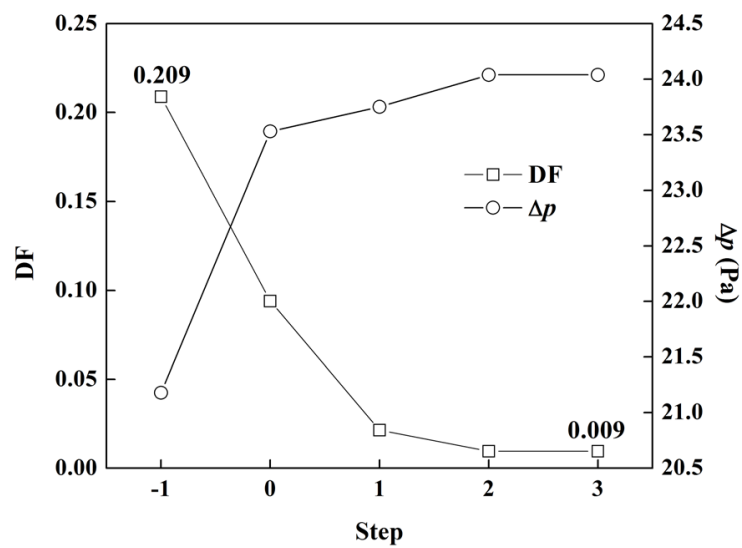

Figure 7. Deviation factor (DF) and pressure drop $(\Delta p)$ as a function of optimization step (middle inlet-outlet geometry; flat target curve).

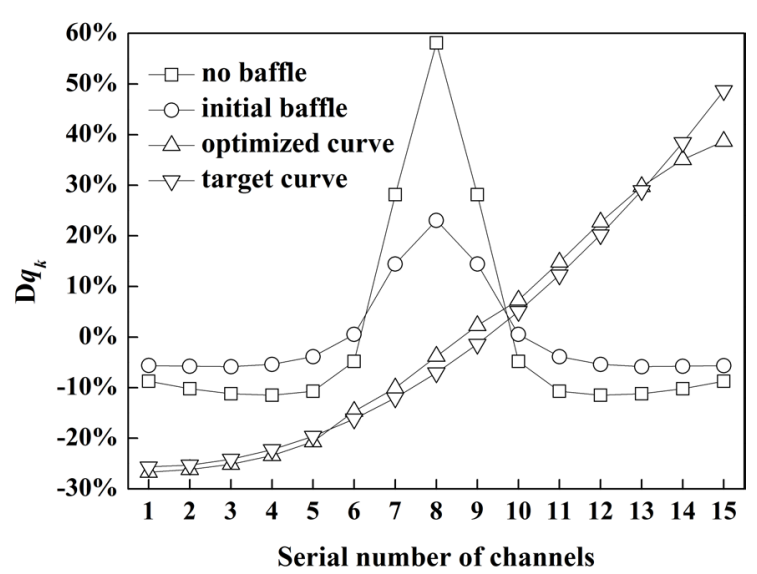

Serial number of channels

7 Figure 8. Flow distribution among parallel channels (middle inlet-outlet geometry; ascending target curve). 


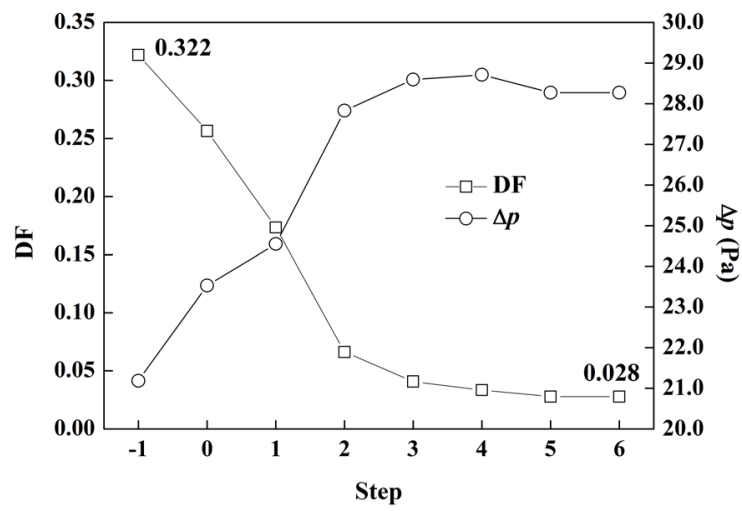

Figure 9. Deviation factor (DF) and pressure drop $(\Delta p)$ as a function of optimization step (middle inlet-outlet geometry; ascending target curve).

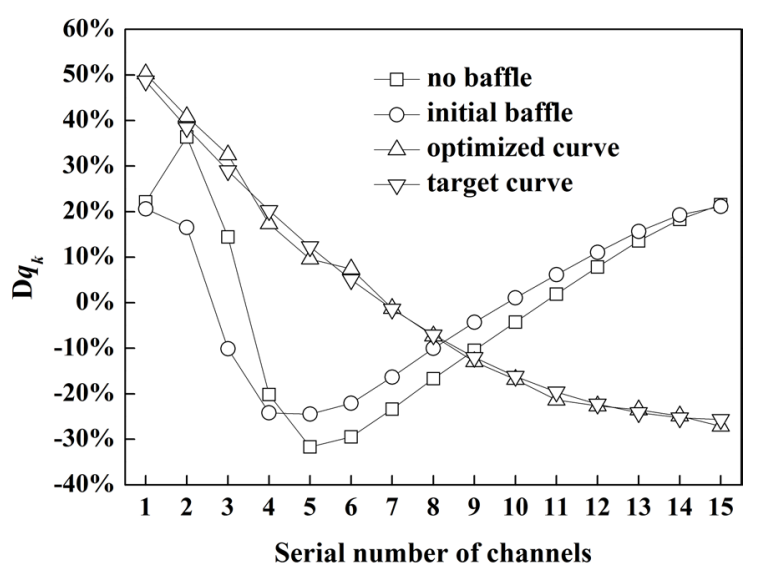

5 Figure 10. Flow distribution among parallel channels (diagonal inlet-outlet geometry; descending target curve).

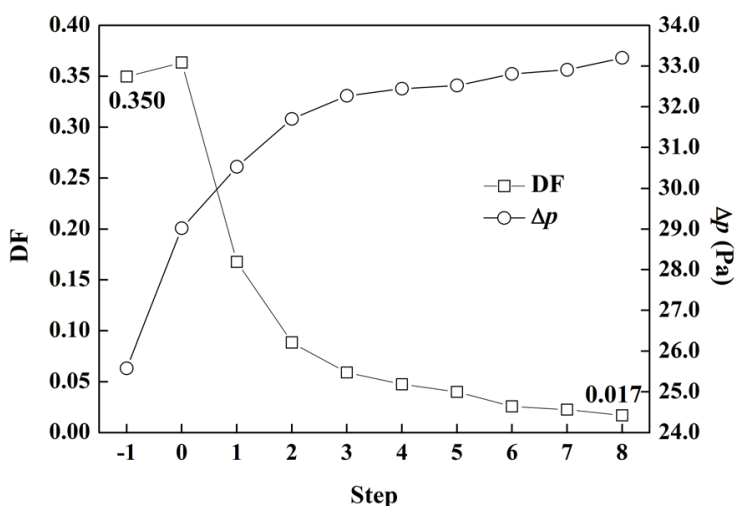

Figure 11. Deviation factor (DF) and pressure drop $(\Delta p)$ as a function of optimization step (diagonal inlet-outlet geometry; descending target curve). 


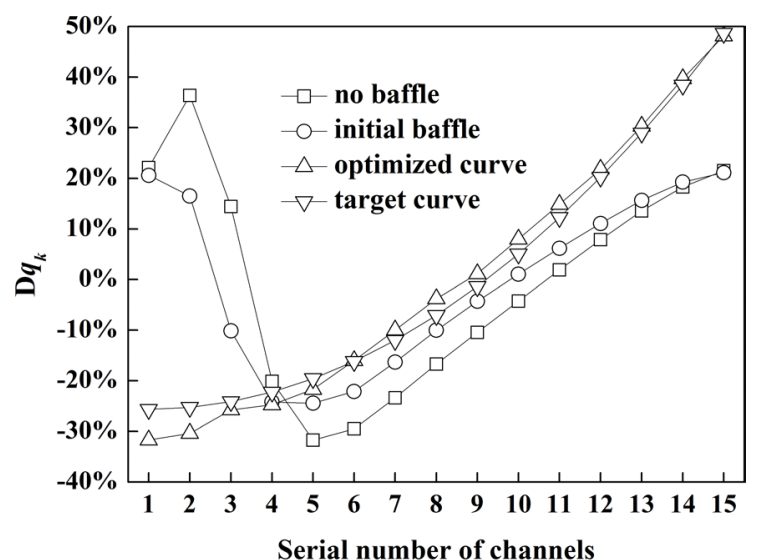

Serial number of channels

2 Figure 12. Flow distribution among parallel channels (diagonal inlet-outlet geometry; ascending target curve).

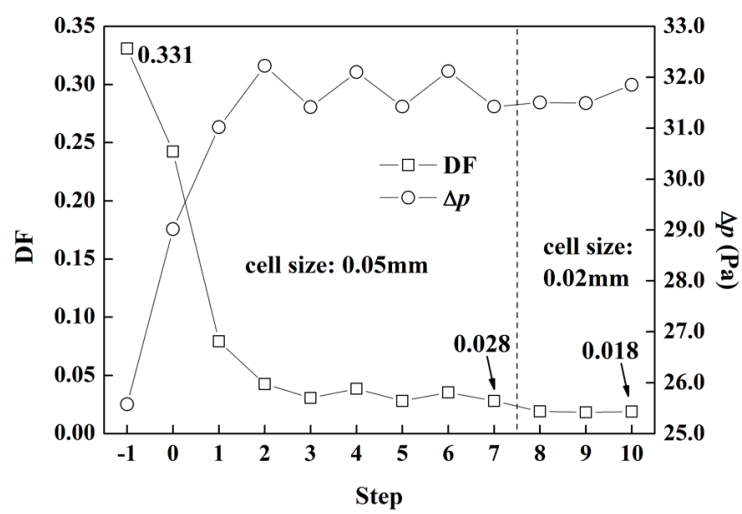

Figure 13. Deviation factor (DF) and pressure drop $(\Delta p)$ as a function of optimization step, influence of mesh density (diagonal inlet-outlet geometry; descending target curve).

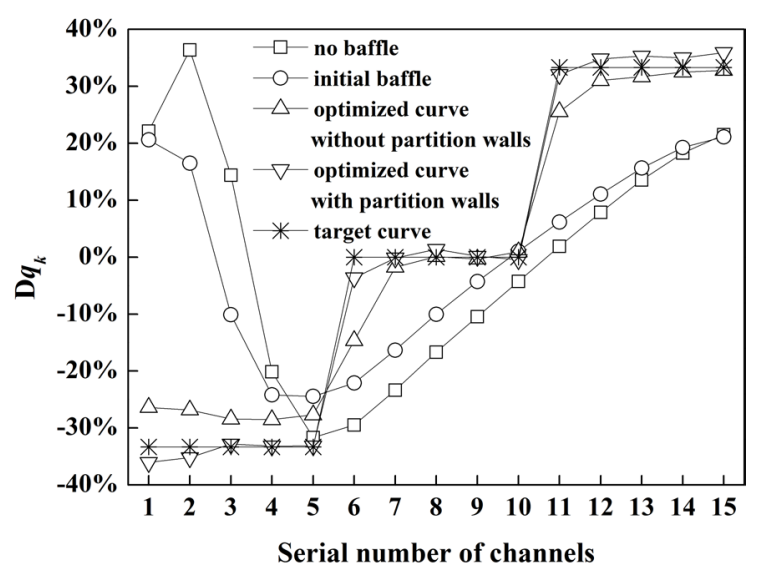

Figure 14. Flow distribution among parallel channels, effect of partition walls (diagonal inlet-outlet geometry; step-like target curve). 
(a)

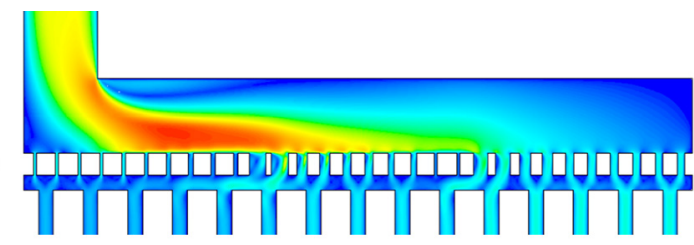

(b)
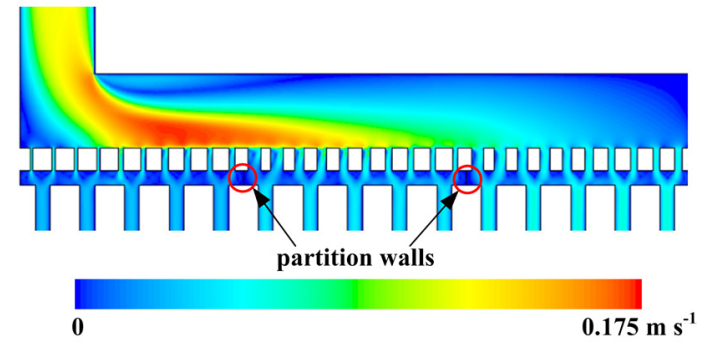

$2 \quad$ Figure 15. The effect of parathion walls on the flow field. (a) without partition walls; (b) with partition walls.

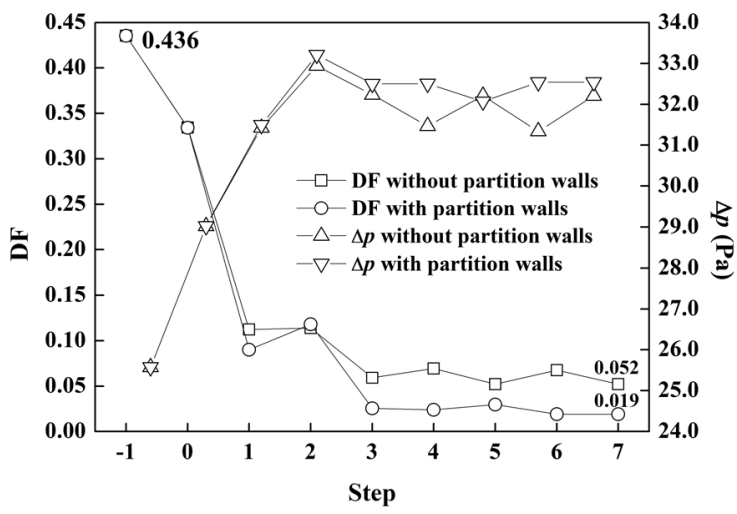

Figure 16. Deviation factor (DF) and pressure drop $(\Delta p)$ as a function of optimization step, effect of partition walls (diagonal inlet-outlet geometry; step-like target curve).

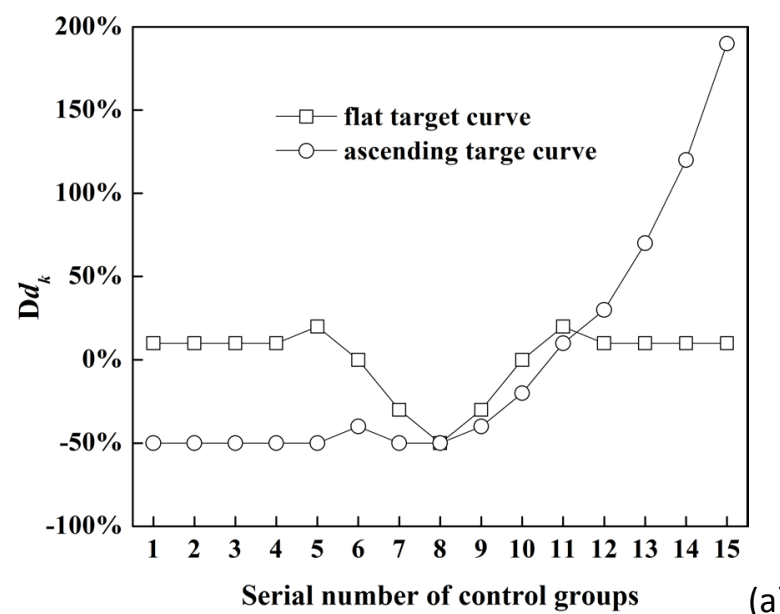




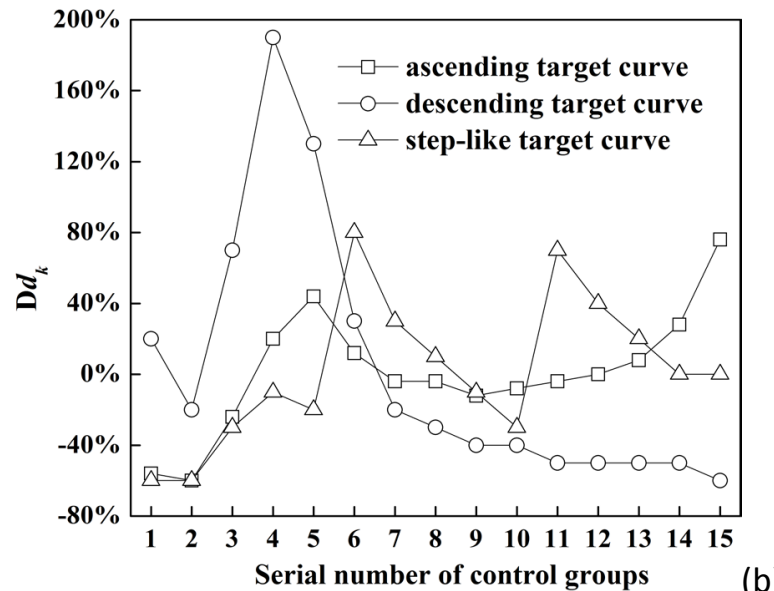

Figure 17. Optimal dimensions of orifices for different target curves. (a) middle inlet-outlet geometry; (b) diagonal inlet-outlet geometry. 